\title{
Theoretical Study of the Chemical Properties and the Reaction Pathway of Decarbonylative Alkylative Esterification of Styrenes with Aliphatic Aldehydes
}

\author{
Meysam Madahi (D), Dadkhoda Ghazanfari, and Sayed Ali Ahmadi \\ Department of Chemistry, Kerman Branch, Islamic Azad University, Kerman, Iran \\ Correspondence should be addressed to Meysam Madahi; madahimeysam@yahoo.com
}

Received 2 October 2021; Revised 14 January 2022; Accepted 29 January 2022; Published 18 February 2022

Academic Editor: Patricia E. Allegretti

Copyright (c) 2022 Meysam Madahi et al. This is an open access article distributed under the Creative Commons Attribution License, which permits unrestricted use, distribution, and reproduction in any medium, provided the original work is properly cited.

\begin{abstract}
Using inexpensive and available aliphatic aldehydes as an alkyl source is a useful and cost-effective way to extend the chain of benzyl esters; this decarbonylative alkylative esterification of styrene derivatives has been used for organic synthesis and medical chemistry. A cocatalyzed decarbonylative alkylative esterification of styrene derivatives with aliphatic aldehydes and iodobenzenediacetate to provide chain elongated benzoates was investigated by the density functional theory, and quantum theory of atoms in molecules analysis has been used. The chemical properties and the reaction pathway between styrene and aldehyde derivatives in the presence of $\mathrm{PhI}(\mathrm{OAc})_{2}$ and $\mathrm{Co}(\mathrm{OAc})_{2}$ have been studied. Chemical properties of styrene and aldehyde derivatives for detecting the stability of products were studied using HOMO and LUMO, potential electronic chemical, global hardness, and global electrophilicity power. The molecular electron potential results show that the styrene and its derivatives are electron donors and aldehyde derivatives are electron acceptors. The localized orbital locator, electron location function analysis, and quantum theory of atoms in the molecule have been used to study the active sites for interactions between reactants. The decarbonylative alkylative esterification was restricted exclusively to cobalt catalysts. The step of ligand exchange was the ratedetermining step for this reaction.
\end{abstract}

\section{Introduction}

Aldehydes are inexpensive and readily available compounds that are used in the reactions of decarbonylative couplings by rhodium, cobalt, or ruthenium [1-3]. Aldehydes are used in regioselectivity reactions of the $\mathrm{CHO}$-functional group such as Diels-Alder [4] and domino oxa-Michael-aldol [5]. Different ways of removing functional groups from organic molecules are very important in the industry $[6,7]$. Direct esterification of alkenes is an important step in converting large petrochemical molecules to esters as target molecules or synthetic intermediates [8]. In the past, alkenes were esterified by the addition of electrophilic acids. In the esterification reaction of alkenes, an alkyl group and an ester group are attached to the $\mathrm{C}=\mathrm{C}$ bond simultaneously. This reaction increases the reactivity of the products. Therefore, alkylative esterification of alkenes is an interesting and useful conversion that is challenging at the same time. In this regard, the carbonylation of aldehydes by metal has been considered for decades [9-11]. In early 1965, Tsuji [12] decarbonylation of aldehydes by stoichiometric quantities of Wilkinson catalysts has been reported to produce a mixture of alkanes, alkenes, and stable inorganic products. $\mathrm{PhI}(\mathrm{OAc})_{2}$ is used as an oxidizing agent in organic chemistry which is capable of oxidizing cobalt to its higher valence [13-15].

Several methods have been proposed regarding esterification of alkenes which can mainly be divided into two categories: for type I, by connecting alkyl and ester groups which are correlated to alkenes and to generate alkyl radicals 
via decarboxylation $[16,17]$. For the type II, the ester and alkyl groups onto the alkenes which are uncorrelated and coming from different sources $[18,19]$.

Generally, experimental methods establish indirect information about the reactions and products geometries; getting the details of mechanisms is difficult. One of the main aspects of recognizing the appropriateness of the theory for predicting interactions is based on the measurement criteria with laboratory properties and measured values. According to the frontier molecular orbitals theory, the high amount of highest occupied molecular orbital (HOMO) energy indicates the tendency of the molecule to lose electrons. Also, low amounts of lowest unoccupied molecular orbital (LUMO) energy indicate the ability of the molecule to accept electrons from other molecules. Quantum theory of atoms in molecule (QTAIM) analysis [20], the localized orbital locator (LOL) [21], and electron location function (ELF) [22] were calculated on the M05-2X to explain properties which can be used to connect the changes in charge of atoms in the molecules. M05-2X is a suitable choice, which can also reasonably represent dispersion interaction. In the present paper, quantum descriptors, including the energy of gap (ELUMO-EHOMO), hardness ( $\eta$ ), dipole moments, chemical potential $(\mu)$, and electrophilicity index $(\omega)$ have been calculated and discussed. Theoretical calculations have been done to elucidate the stability of productions. Initially, the use of a radical initiator resulted in the removal of the carbonyl group from the aldehyde. Alkyl radicals of aldehyde derivatives are highly active and attack the styrene conjugate that produces the radical compound.

\section{Experimental Section}

2.1. Computational Methods. All calculations were performed using Gaussian 09 package [23]. For the isolated species and complexes, we have used M05-2X level of theory to study the geometric, electronic, and vibrational properties. The initial structure of styrene (1), 4-methoxylstyrene (1a), 4-tert-butylstyrene (1b), 4-methylstyrene (1c), 4-chloromethylstyrene (1d),4-trifluoromethylstyrene (1e), 4-chlorostyrene (1f), 3-chlorostyrene (1g), 2-chlorostyrene (1h), 4-fluorostyrene (1i), 4-boromostyrene (1j), 3-boromostyrene $(1 \mathrm{k})$, trans-1,2-diphenylethene $(1 \mathrm{~L})$, as well as derivatives of aldehydesuch asisobutyraldehyde (2a), pivaldehyde (2b),2-methylbutanal (2c),2-ethylbutanal (2d),2-ethylhexanal (2e), cyclohexanecarbaldehyde (2f), cyclopentanecarbaldehyde( $2 \mathrm{~g}), 3,5,5$-trimethylhexanal $(2 \mathrm{~h})$, 3-methylbutanal (2i),3,3-dimethylbutanal (2j), propionaldehyde (2k), and (diacetoxyiodo) benzene $\mathrm{PhI}(\mathrm{OAc})_{2}$ were drawn by Gauss view software. The stationary points were determined by frequency calculations in order to ensure that all reactants, intermediates, and products have zero imaginary frequency, and each transition state has only one imaginary frequency and have verified by the internal reaction coordinate (IRC) calculations, at the same level of theory, to confirm that the structures of the transition states led to the corresponding reactants and products. The stoichiometric ratio of $1: 1$ is considered for the reactants. The reaction between reactants is performed without any restrictions. Various aspects of investigations on created bonding were studied. Molecular electrostatic potential (MEP), ELF, and LOL are effective ways to predict possible locations of interactions. Quantum theory of atoms in the molecule (QTAIM) [24, 25] method was performed to study the nature of interactions of complexes by employing Multiwfn program [26]. All geometric optimization processes are followed by vibrational spectral analysis to ensure that optimized structures are located at the potential energy surfaces. The first guesstimate to the transition state (TS) was performed with QST2, and the intrinsic reaction coordinate (IRC) was estimated later at the same theory level. Afterwards, starting from the IRC results, the resultant structures for reactants and products were taken and used as initial guess for QST3 calculation, and the IRC was calculated.

Theoretical calculation method calculates the chemical properties of molecules by considering the effects of electron correlation. Theoretical calculations require less cost and time compared to laboratory methods. The energy and pathway of reaction between reactants are achieved by using the M05-2X level of theory [27]. The main goal of this work is to characterize the electronic and structural nature and pathway of reaction of the corresponding reactants and products. The optimized structures are depicted in Figure 1.

The reaction pathway of decarbonylative alkylative esterification of styrene derivatives with aliphatic aldehydes has been calculated. Styrene, isobutyraldehyde, and iodobenzenediacetate were chosen as the model substrates. DTBP (di-tert-butyl peroxide) has been used as the radical initiator of the reaction. The use of DTBP leads to the removal of aldehyde hydrogen from isobutyraldehyde, and then the carbonyl group is separated from the aldehyde structure. As a result, the active alkyl radical group (II) remains. In the following intermolecular hydrogen atom abstraction of the isobutyraldehyde, spontaneous decarbonylation and insertion in the $\mathrm{C}=\mathrm{C}$ bond of styrene provide benzyl radical III that coordinates to the $\mathrm{Co}(\mathrm{II})$ catalyst to create $\mathrm{Co}$ (III) complex IV. Addition of $\mathrm{PhCO}_{2}{ }^{-}$to the reaction medium results in the exchange of ligand in complex IV, and this ligand exchange crosses transition state 1 (TS1). The reductive elimination in structure V with TS2 results in the formation of 3-methyl-1-phenylbutyl acetate (3a) and $\mathrm{Co}^{\mathrm{I}}(\mathrm{OAc})$. $\mathrm{PhI}(\mathrm{OAc})_{2}$ can oxidize the $\mathrm{Co}^{\mathrm{I}}(\mathrm{OAc})$ compound and recover the $\mathrm{CO}^{\mathrm{II}}(\mathrm{OAc})_{2}$ catalyst (Scheme 1). The energy profile of the reaction pathway is shown in Scheme 2.The energy of transition states TS1 and TS2 for all compounds $(\mathrm{kJ} / \mathrm{mol})$ (reaction A: styrene and its derivatives (1a-1l) with isobutyraldehyde; reaction B: aldehyde derivatives (2b-2k) with styrene) are reported in Table 1.

The reaction energy for all the products obtained is reported in Figure 2. Various styrene derivatives bearing electron donating or withdrawing substituents on the phenyl moiety smoothly underwent this three-component decarbonylative cascade reaction to afford the desired alkylated esters in good yields, such asmethoxy (1b), tert-butyl (1c), methyl (1d), chloromethyl (1e), tirfluoromethyl (1f), and halo (1g-11). Among them, the optimized reaction condition could be applied to the styrene derivatives with chlorosubstituted at para, meta, and ortho position (1g, 1h, and 1i), 

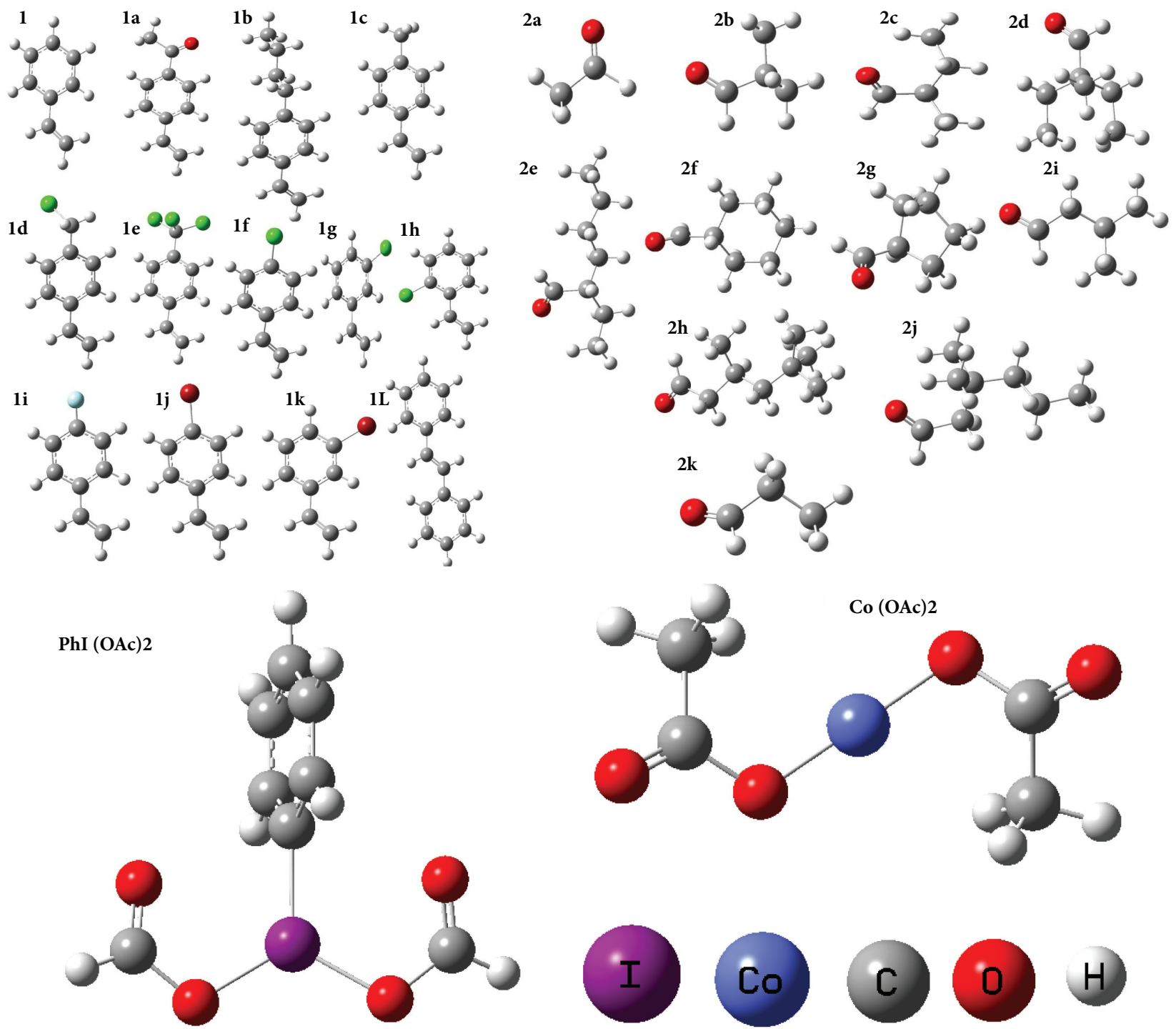

Figure 1: The most stable structures of styrene and aldehyde derivatives, $\mathrm{PhI}(\mathrm{OAc})_{2}$ and $\mathrm{Co}(\mathrm{OAc})_{2}$.

and similar yields were obtained, which reveal no obvious substituent effect. The energy of the chlorine substitution reaction in styrene derivatives is the same for all positions. The reaction energy of styrene derivatives with bromosubstituted at para and meta position (1 $\mathrm{k}$ and $1 \mathrm{l})$ is similar, which is characterized by substitutions have no effect. Cobalt(II) acetate tetrahydrate $\left(\mathrm{Co}^{\mathrm{II}}(\mathrm{OAc})_{2}\right)$ has been employed as an efficient catalyst. The $1 \mathrm{~m}$ molecule is a suitable substrate and can be transformed into the corresponding product $3 \mathrm{~m}$; this reaction is sensitive for the steric changes on the alkenes, as observed in the experiment; $\alpha$-methyl styrenes are inactive in the alkylative esterification. The productions of alkylative esterification of styrene with different aliphatic aldehydes (2a-2k) and aldehyde (2a) with styrene derivatives $(2 a-11)$ were $3 a-3 m$ and $4 a-4 k$ have been shown in Figure 3, respectively.

To clarify the nature of electronic transitions in the corresponding reaction, molecular properties, such as chemical potential $(\mu)$, are calculated as follows:

$$
\mu=\frac{(I+A)}{2} .
$$

The hardness $(\eta)$ is

$$
\eta=\frac{(A-I)}{2} .
$$

And, global electrophilicity index $(\omega)$ is

$$
\omega=\frac{\mu^{2}}{2 \eta}
$$

where $I$ is the ionization potential, and equal to $\mathrm{E}_{\mathrm{HOMO}}$, and $A$ is electron affinity and can be introduced as $A=\mathrm{E}_{\mathrm{LumO}}$.

The energy level of the boundary molecular orbitals provides useful information on the chemical reaction indicator. Therefore, the reaction path can be examined in more detail. $\mu, \eta, \mathrm{S}$, and $\omega$ of all reactants are presented in Table 2. As can be seen in Table 2 , the $\mu$ values of aldehyde radicals (II), styrene and its derivatives are negative, 

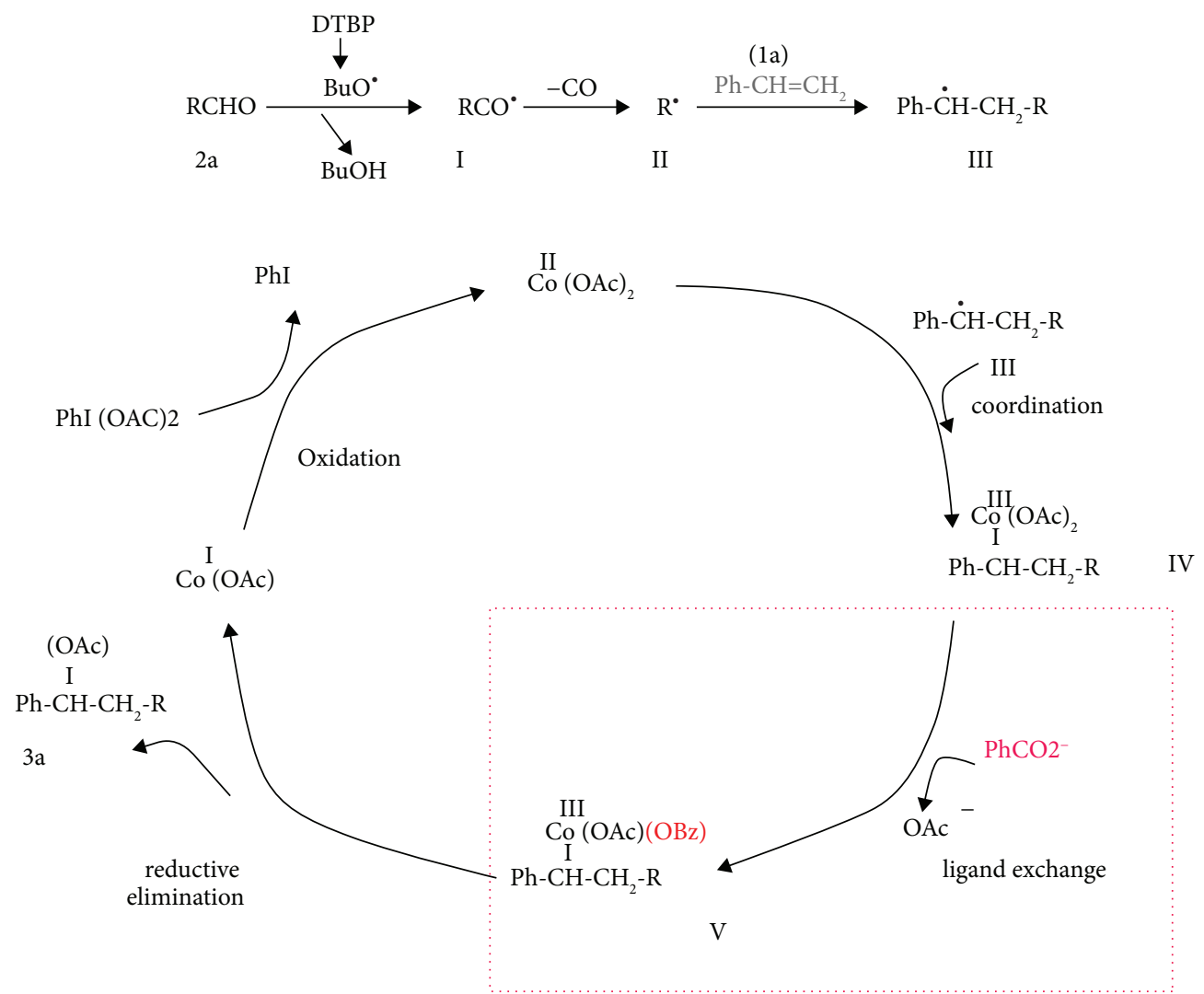

Scheme 1: Possible pathway of the decarbonylative alkylative esterification of 1a with $2 \mathrm{~b}$ in the presence of $\mathrm{PhI}(\mathrm{OAc})_{2}$ and $\mathrm{Co}(\mathrm{OAc})_{2}$.

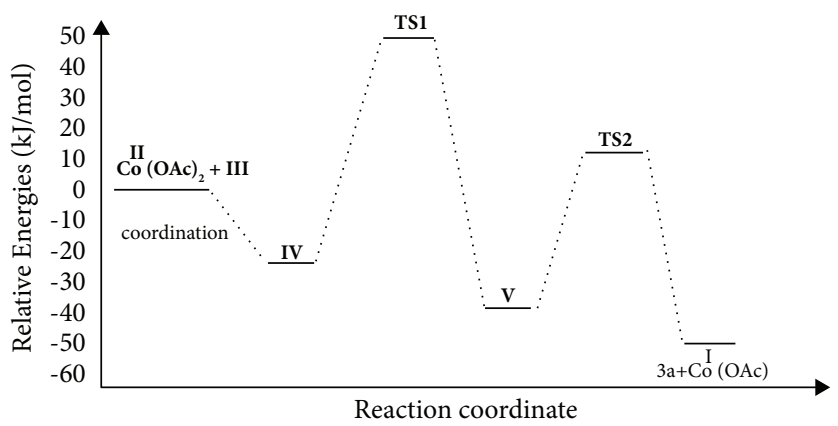

Scheme 2: The energy profile of the reaction pathway at the M05-2X level of theory (unit: $\mathrm{kJ} / \mathrm{mol}$ ).

TABLE 1: Energy of transition states TS1 and TS2 for all compounds $(\mathrm{kJ} / \mathrm{mol})$.

\begin{tabular}{|c|c|c|c|c|c|c|c|}
\hline A (product) & TS1 & TS2 & Energy & B (product) & TS1 & TS2 & Energy \\
\hline $3 a$ & 30.1 & 43.2 & -50.2 & $4 \mathrm{~b}$ & 40.4 & 52.8 & -45.6 \\
\hline $3 b$ & 33.4 & 45.2 & -35.3 & $4 c$ & 38.6 & 51.0 & -44.3 \\
\hline $3 c$ & 32.4 & 41.6 & -43.6 & $4 d$ & 37.1 & 49.2 & -48.5 \\
\hline $3 d$ & 31.2 & 42.3 & -45.8 & $4 \mathrm{e}$ & 41.3 & 45.1 & -52.7 \\
\hline $3 e$ & 33.5 & 44.2 & -47.4 & $4 \mathrm{f}$ & 45.2 & 51.4 & -48.2 \\
\hline $3 f$ & 28.59 & 38.6 & -45.66 & $4 \mathrm{~g}$ & 48.1 & 55.9 & -45.1 \\
\hline $3 g$ & 32.8 & 42.1 & -50.6 & $4 \mathrm{~h}$ & 35.1 & 44.1 & -47.3 \\
\hline $3 \mathrm{~h}$ & 34.0 & 46.8 & -49.4 & $4 \mathrm{i}$ & 30.3 & 39.4 & -50.3 \\
\hline $3 \mathrm{i}$ & 35.7 & 48.6 & -47.5 & $4 \mathrm{j}$ & 32.1 & 40.1 & -48.5 \\
\hline $3 \mathrm{j}$ & 33.2 & 44.3 & -59.6 & $4 \mathrm{k}$ & 27.8 & 38.9 & -49.2 \\
\hline $3 \mathrm{k}$ & 33.7 & 45.1 & -54.1 & & & & \\
\hline 31 & 33.9 & 45.7 & -53.8 & & & & \\
\hline $3 \mathrm{~m}$ & 35.8 & 49.9 & -55.7 & & & & \\
\hline
\end{tabular}

Reaction A: styrene and its derivatives (1a-1l) with isobutyraldehyde; reaction B: aldehyde derivatives (2b-2k) with styrene. 


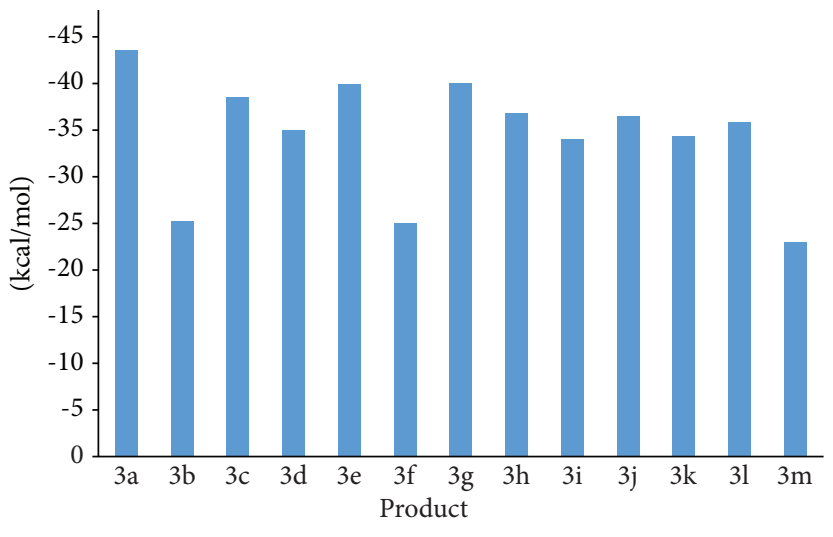

(a)

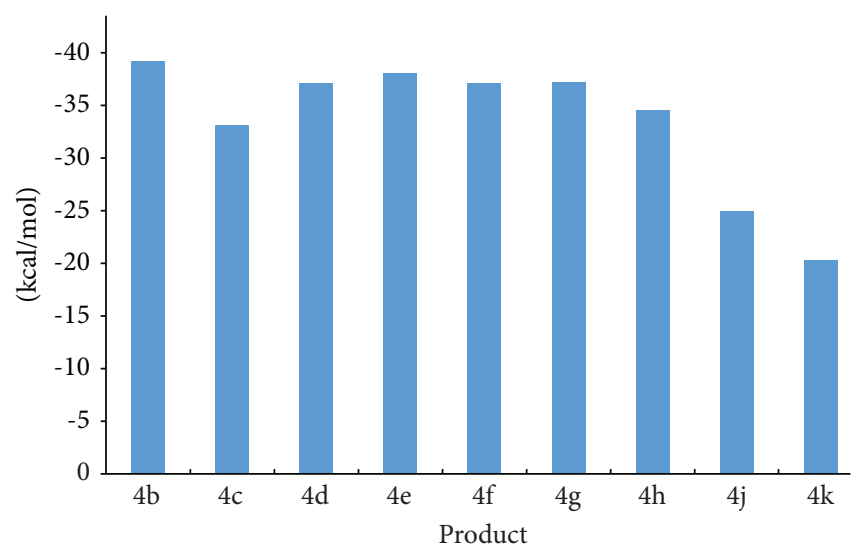

(b)

Figure 2: Reaction energy between $1 \mathrm{a}-1 \mathrm{~m}$ with $2 \mathrm{a}-2 \mathrm{k}$ in the presence of $\mathrm{PhI}(\mathrm{OAc})_{2}$ and $\mathrm{Co}(\mathrm{OAc})_{2}$.

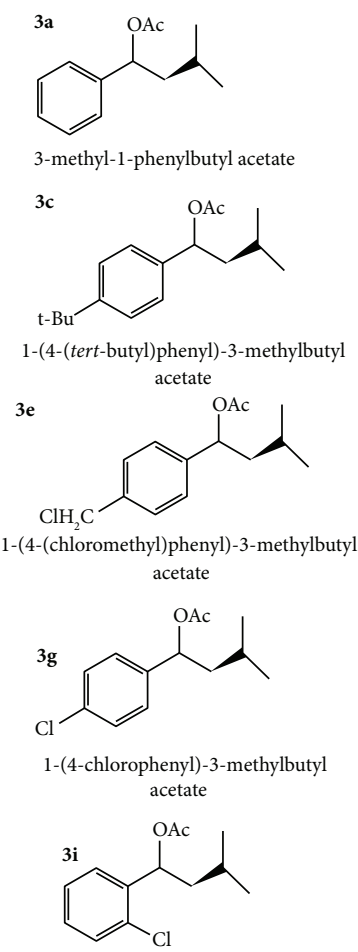

1-(2-chlorophenyl)-3-methylbutyl acetate

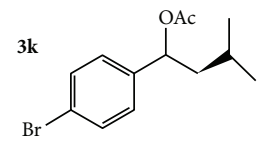

1-(4-bromophenyl)-3-methylbutyl acetate
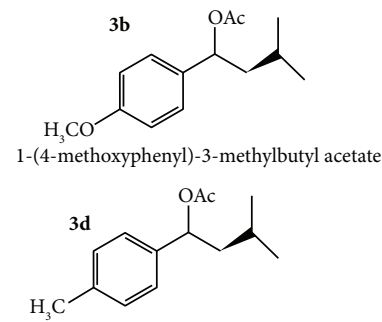

3-methyl-1-(p-tolyl)butyl acetate

$3 \mathbf{f}$

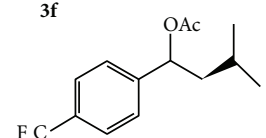

1-(4-(tree fluoro methyl)phenyl)-3-methylbutyl acetate

$3 \mathrm{~h}$<smiles>CC(=O)OC(CC(C)C)c1cccc(Cl)c1</smiles>

1-(3-chlorophenyl)-3-methylbutyl

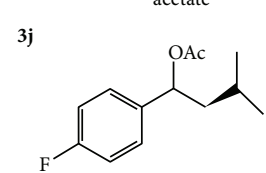

1-(4-fluorophenyl)-3-methylbutyl acetate

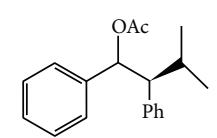

(2S)-3-methyl-1,2-diphenylbutyl acetate

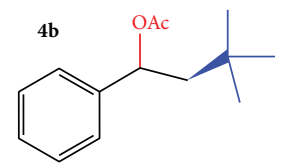

3,3-dimethyl-1-phenylbutyl acetate

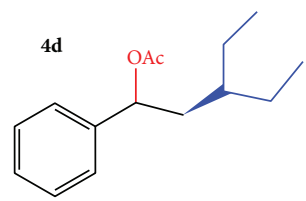

3-ethyl-1-phenylpentyl acetate

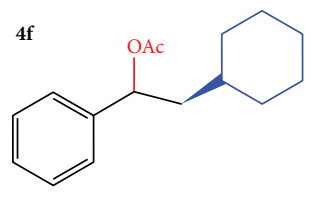

2-cyclohexyl-1-phenylethyl acetate

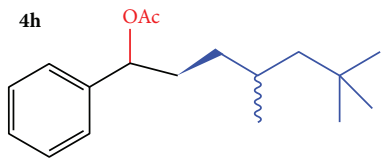

4,6,6-trimethyl-1-phenylheptyl acetate

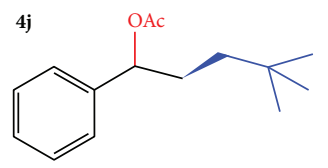

4,4-dimethyl-1-phenylpentyl acetate

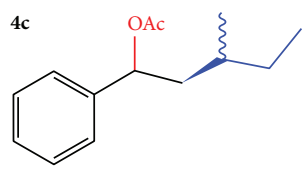

3-methyl-1-phenylpentyl acetate

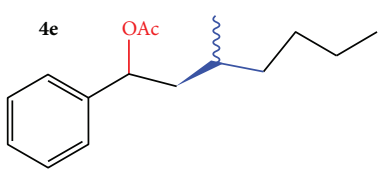

3-methyl-1-phenylheptyl acetate
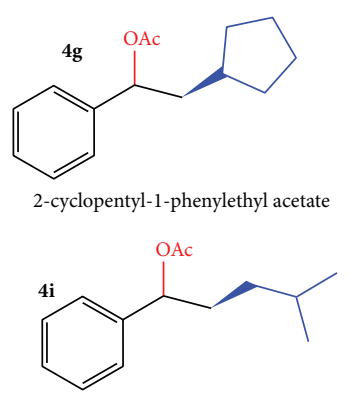

4-methyl-1-phenylpentyl acetate

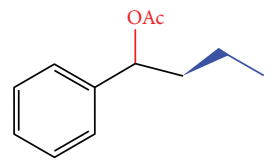

1-phenylbutyl acetate

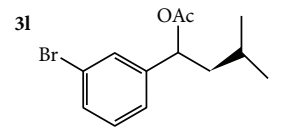

1-(3-bromophenyl)-3-methylbutyl acetate

FIgURE 3: Stable product reaction of styrene derivatives with aldehyde derivatives. 
TABLE 2: HOMO ( $\left.\mathrm{E}_{\mathrm{HOMO}}\right)$ and LUMO ( $\left.\mathrm{E}_{\mathrm{LUMO}}\right)$ energies, and quantum molecular descriptors, all in eV, for styrene derivatives (1a-1l) and aldehyde radicals $(2 \mathrm{a}-2 \mathrm{k})$ and $\mathrm{PhI}(\mathrm{OAc})_{2}$.

\begin{tabular}{|c|c|c|c|c|c|c|}
\hline molecules & $\mathrm{E}_{\text {HOMO }}$ & $\mathrm{E}_{\text {LUMO }}$ & $\mu$ & $\eta$ & $S$ & $\omega$ \\
\hline 1 & -6.14043 & -0.79347 & -3.46695 & 2.673481 & 0.374044 & 2.247962 \\
\hline $1 \mathrm{a}$ & -6.42751 & -1.75865 & -4.09308 & 2.334432 & 0.42837 & 3.588302 \\
\hline $1 b$ & -5.92111 & -0.69742 & -3.30927 & 2.611848 & 0.382871 & 2.096454 \\
\hline $1 c$ & -5.93826 & -0.69007 & -3.31416 & 2.624093 & 0.381084 & 2.092853 \\
\hline $1 d$ & -6.31132 & -1.36654 & -3.83893 & 2.472391 & 0.404467 & 2.980387 \\
\hline $1 \mathrm{e}$ & -6.63159 & -1.72871 & -4.18015 & 2.451439 & 0.407924 & 3.563965 \\
\hline 1f & -6.27377 & -1.12218 & -3.69797 & 2.575793 & 0.38823 & 2.654526 \\
\hline $1 \mathrm{~g}$ & -6.44873 & -1.1396 & -3.79417 & 2.654569 & 0.376709 & 2.711494 \\
\hline $1 \mathrm{~h}$ & -6.3739 & -1.13415 & -3.75403 & 2.619875 & 0.381698 & 2.689582 \\
\hline $1 \mathrm{i}$ & -6.15077 & -0.87619 & -3.51348 & 2.63729 & 0.379177 & 2.340389 \\
\hline $1 \mathrm{j}$ & -6.14288 & -1.07837 & -3.61063 & 2.532256 & 0.394905 & 2.574114 \\
\hline $1 \mathrm{k}$ & -6.3603 & -1.08735 & -3.72383 & 2.636474 & 0.379294 & 2.629815 \\
\hline $1 \mathrm{~L}$ & -5.62778 & -1.35647 & -3.49212 & 2.135655 & 0.46824 & 2.855079 \\
\hline $2 \mathrm{a}$ & -6.46588 & -0.13116 & -3.29852 & 3.16736 & 0.31572 & 1.717553 \\
\hline $2 b$ & -6.56901 & -0.48 & -3.5245 & 3.044503 & 0.328461 & 2.040092 \\
\hline $2 c$ & -6.65391 & -0.60027 & -3.62709 & 3.026816 & 0.33038 & 2.173205 \\
\hline $2 d$ & -6.58506 & -0.49987 & -3.54246 & 3.042598 & 0.328666 & 2.062226 \\
\hline $2 e$ & -6.56193 & -0.57796 & -3.56995 & 2.991986 & 0.334226 & 2.129777 \\
\hline $2 \mathrm{f}$ & -6.44982 & -0.48027 & -3.46505 & 2.984775 & 0.335034 & 2.011301 \\
\hline $2 g$ & -6.7135 & -0.54912 & -3.63131 & 3.08219 & 0.324445 & 2.139128 \\
\hline $2 \mathrm{~h}$ & -6.47812 & -0.55429 & -3.51621 & 2.961917 & 0.337619 & 2.087111 \\
\hline $2 \mathrm{i}$ & -6.53309 & -0.54476 & -3.53893 & 2.994162 & 0.333983 & 2.091403 \\
\hline $2 j$ & -6.6667 & -0.643 & -3.65485 & 3.01185 & 0.332022 & 2.217557 \\
\hline $2 \mathrm{k}$ & -6.63867 & -0.55973 & -3.5992 & 3.039469 & 0.329005 & 2.131003 \\
\hline $\mathrm{PhI}(\mathrm{OAc})_{2}$ & -6.23839 & -1.79048 & -4.01444 & 2.223955 & 0.449649 & 3.623212 \\
\hline
\end{tabular}

Therefore, it can be concluded that the transfer of electrons from styrene and its derivatives to aldehyde radicals (II) is done.Various styrene derivatives bearing electron donating or withdrawing substituents on the phenyl moiety (1a-1l) smoothly underwent this three-component decarbonylative cascade reaction to afford the desired alkylated esters in good yields. Products formed with aldehyde radicals are thermodynamically more stable than products with styrene derivatives. These values indicate the transfer of electron charge from HOMO styrene and its derivatives to LUMO aldehyde radicals. The values of LUMO-HOMO indicate which of these compounds present high chemical stability. $\mu$ less than zero represents a spontaneous reaction. The electrophilicity is a descriptor of the reactivity that allows a quantitative classification of the global electrophilic nature of a molecule within a relative scale. $\omega$ shows measure of energy lowering due to the maximum electron flow between the donor and the acceptor. According to the definition, this index measures the tendency of chemical species to accept electrons. A more reactive nucleophile is characterized by lower $\mu$ and $\omega$ values, and then a good electrophile is characterized by high $\mu$ and $\omega$ values. The greater $\mu, \eta$, and $\omega$ differences between compounds led to faster reactions. According to the obtained HOMO and LUMO of Figure 4, it can be concluded that ethylene double bonds of styrene derivatives have as electron donors and the aldehyde radicals have the role of electron acceptors.

Electron density is a crucial factor in understanding the reactivity of electrophilic and nucleophilic sites and the interaction of hydrogen bonds. Therefore, MEP of these compounds was simulated to predict this reaction from attacks on nucleophilic and electrophilic sites for all the compounds using the M05-2X level of the optimized geometry.

Computed MEPs for $\mathrm{PhI}(\mathrm{OAc})_{2}$, styrene and aldehyde derivatives are depicted in Figure 5. The blue and red surfaces indicate positive and negative potential regions, respectively. In MEP images, as can be seen, the focus of the red color is on the phenyl ring of styrene; due to the concentration of HOMO orbitals on the phenyl ring, it can be concluded that styrene derivatives tend to give electrons from the phenyl ring. Aldehyde radicals play an electron accepting role, as can be seen on the aliphatic part of aldehyde, the focus of the LUMO orbitals is very low, and the blue color in the images MEP indicates a lack of electrons in this part. The MEP plots of $\mathrm{PhI}(\mathrm{OAc})_{2}$, styrene, and aldehyde derivatives suggest that the red surfaces, which are rich in electrons, interact with the blue surfaces.

One of the most useful methods for the examination of bond strength is QTAIM; this method provides accurate quantitative information about the electronic structure. This theory explains the concepts of chemical bonding and their associated properties. Topological parameters are a suitable tool for determining the bond strength. Surface analysis based on covalent bonds provides ELF and LOL maps, which indicates regions of molecular space where an electron pair is more likely to be found [22]. ELF and LOL images have drawn using Multiwfn. The chemical concept of LOL and ELF is similar because they both depend on the kinetic energy density. ELF images were created by considering the electron pair density, and LOL show that gradients of 

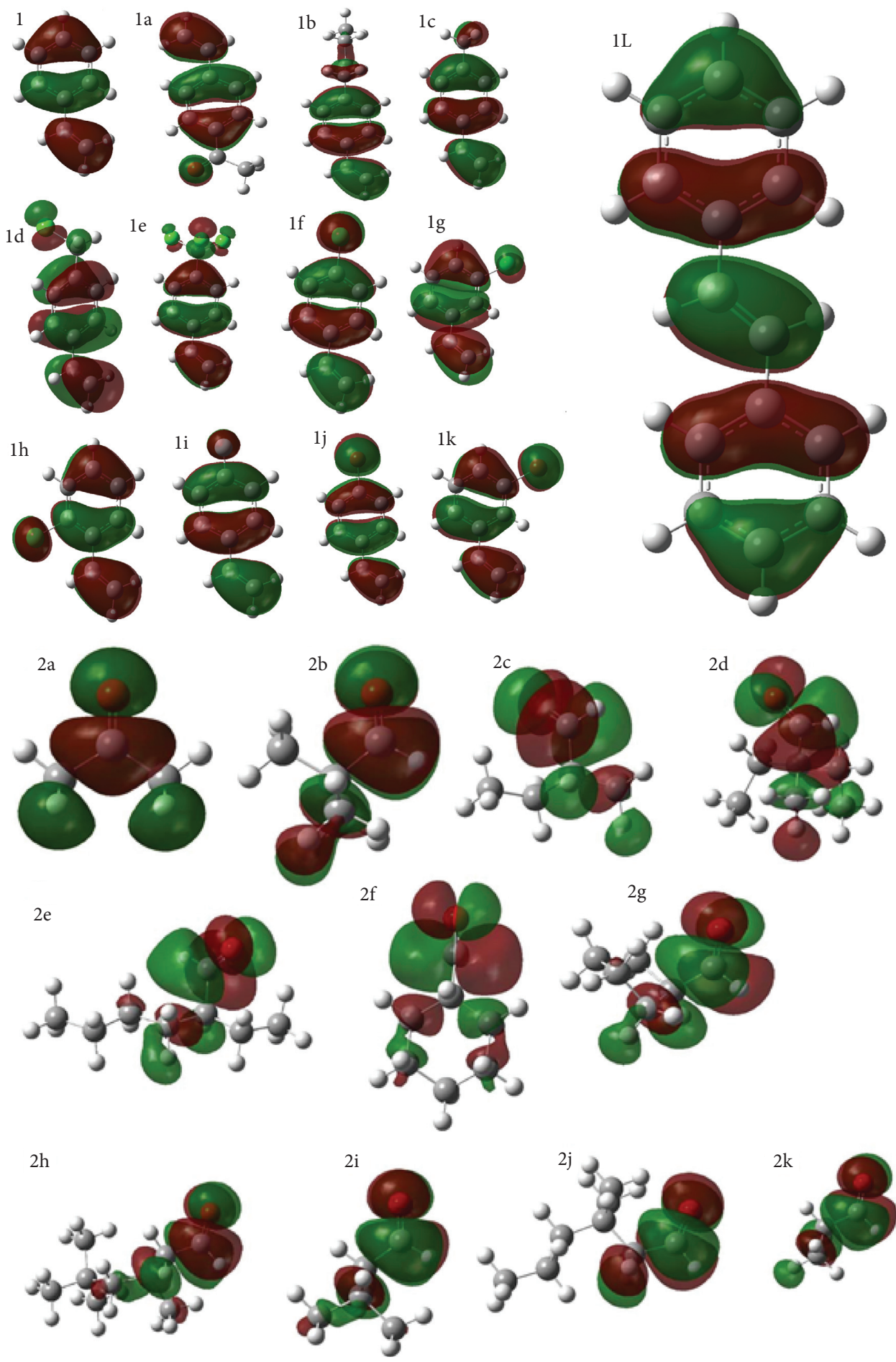

Figure 4: Atomic orbitals HOMO of styrene derivative ( $1 \mathrm{a}-1 \mathrm{~m})$ and atomic orbitals LUMO of aldehyde (2a-2k). 


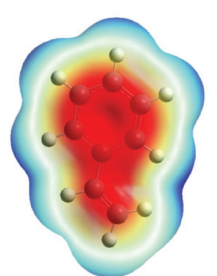

1

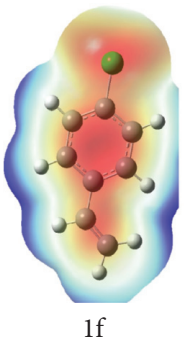

If

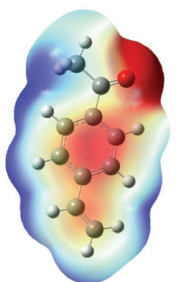

$1 \mathrm{a}$

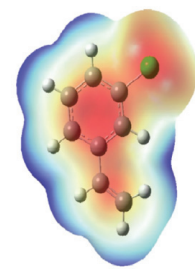

$1 \mathrm{~g}$

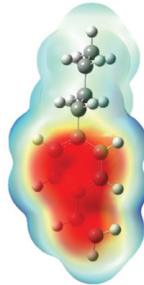

$1 \mathrm{~b}$

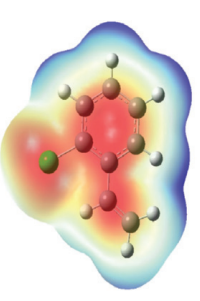

$1 \mathrm{~h}$

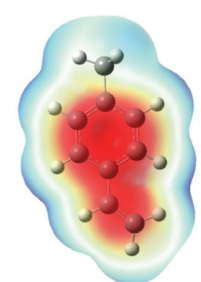

$1 c$

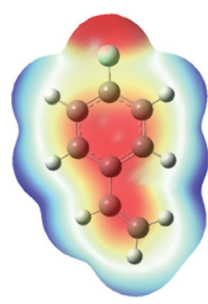

$1 \mathrm{i}$

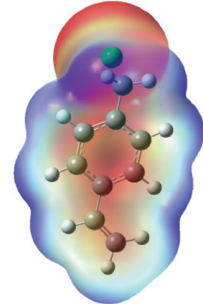

1d

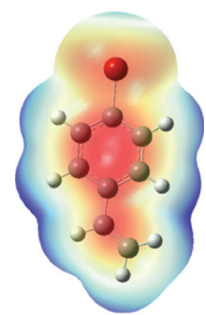

$1 \mathrm{j}$

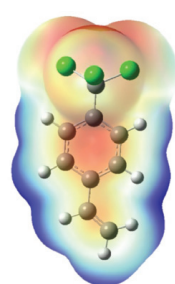

le

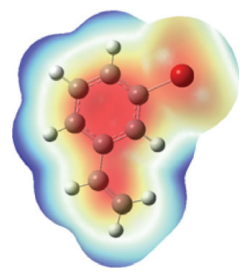

$1 \mathrm{k}$

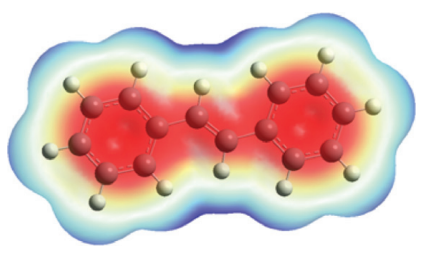

11

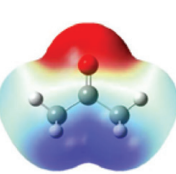

$2 \mathrm{a}$
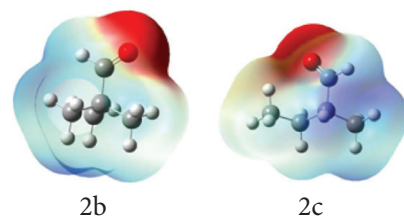

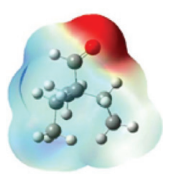

$2 \mathrm{~d}$
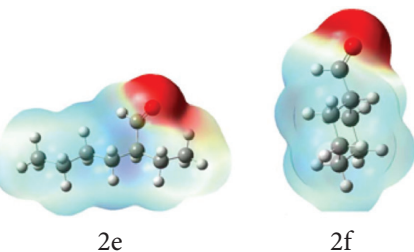
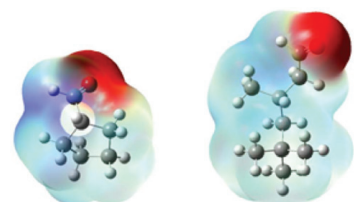

$2 \mathrm{~h}$

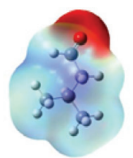

$2 \mathrm{i}$

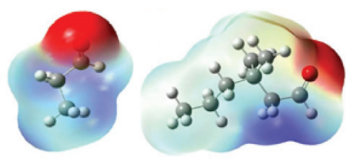

$2 \mathrm{j}$

2k

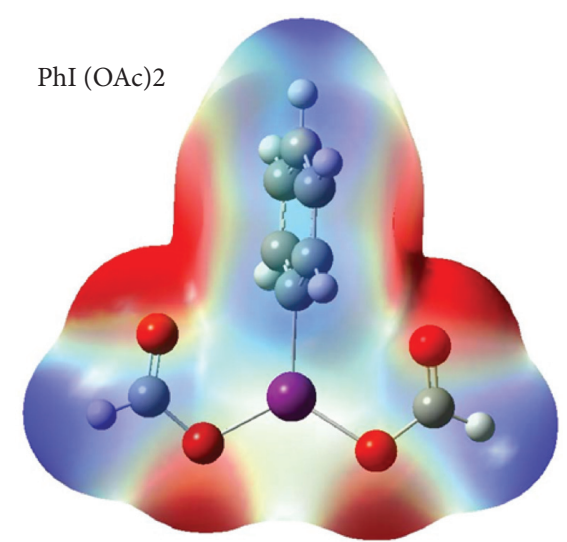

Figure 5: Electron density (isovalue $=0.004$ ), mapped with molecular electrostatic potential (color scheme: red for negative surface map values and blue for the positive ones) for styrene and aldehyde derivatives. 

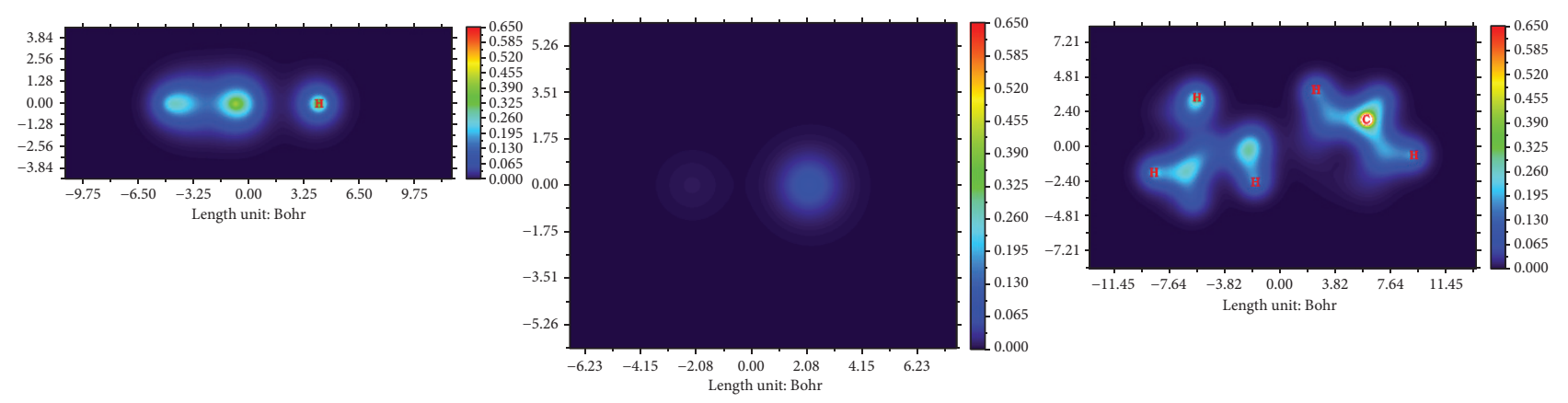

(a)
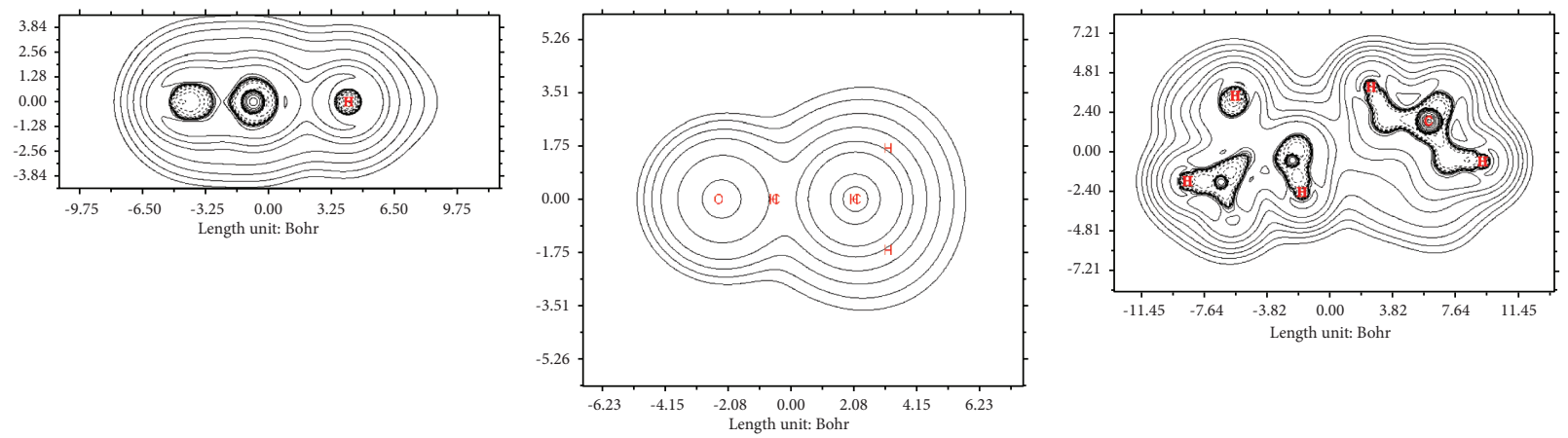

(b)
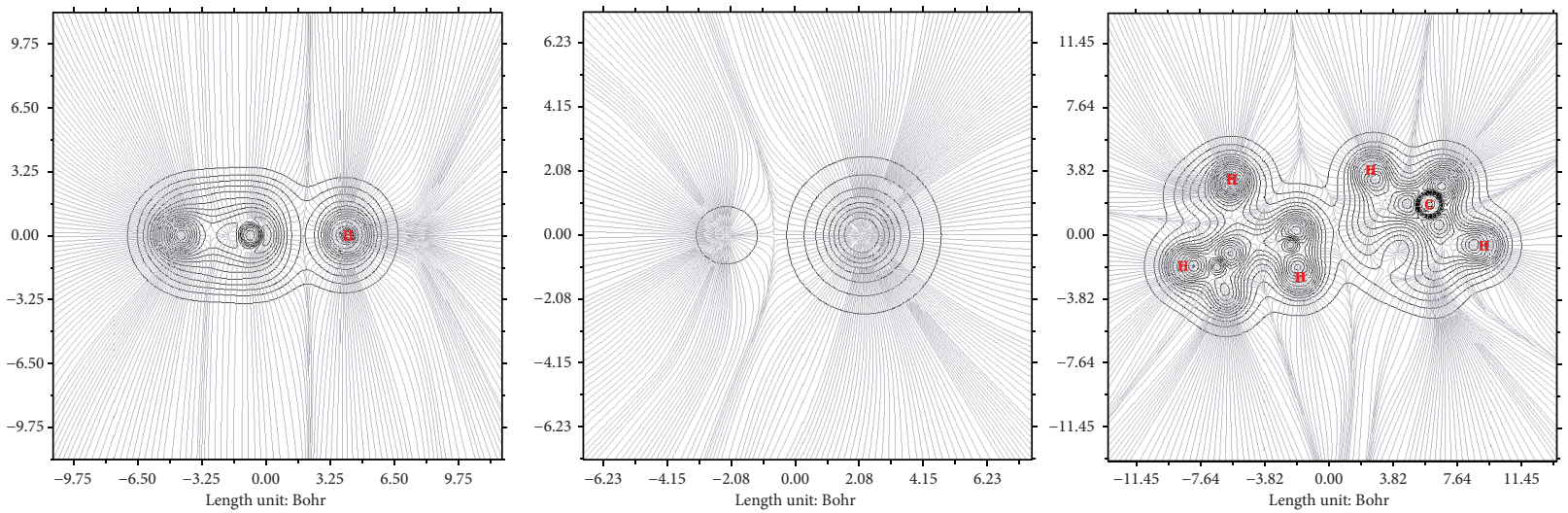

(c)
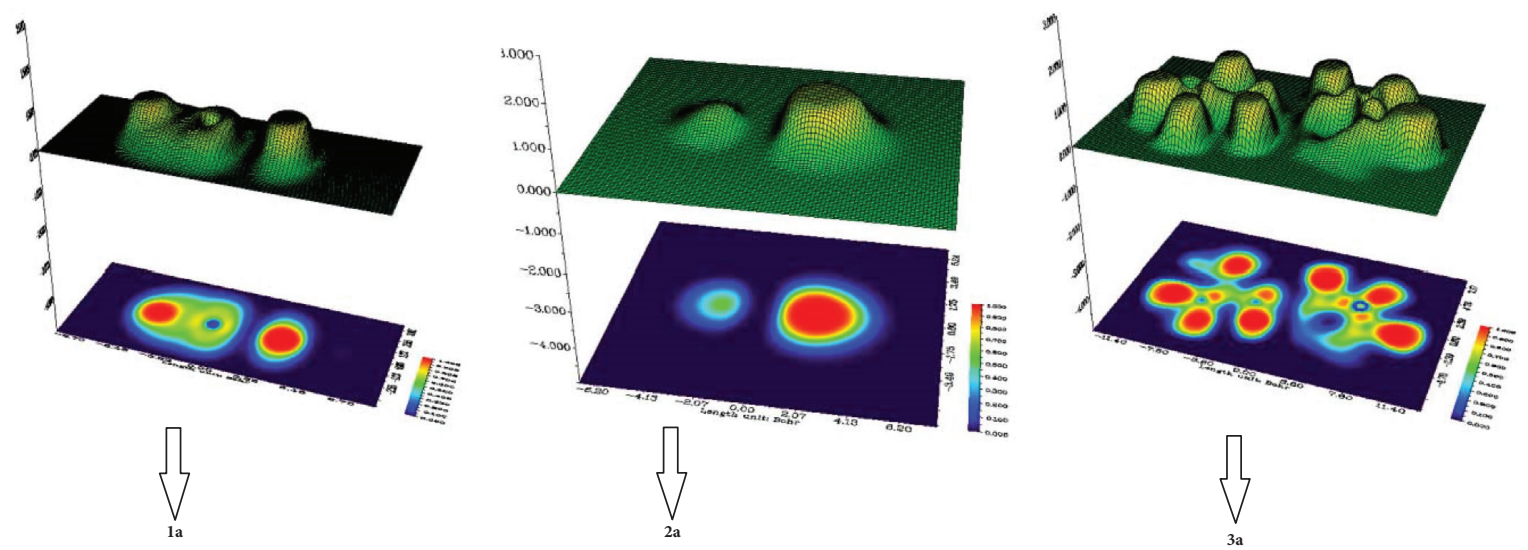

(d)

Figure 6: Contour map of (a) electron density, (b) electron density Laplacian, (c) LOL, and (d) ELF of 1a, 2a, and 3a molecules. 
localized orbitals are maximized when localized orbitals overlap. Color and contour maps of ELF and LOL for the molecule of styrene (1a), isobutyraldehyde (2a), and 3-methyl-1-phenylbutyl acetate (3a) are shown in Figure 6. The blue regions around hydrogen atoms show the delocalized electron cloud around it. The covalent regions are seen between bonds in 3a molecule, indicated by red color with high electron density, electron density Laplacian and ELF values, and the electron depletion regions between valence shell and inner shell are shown by the blue circles around the carbon. From Figure 6(d), the high ELF regions are seen around double bond and oxygen atoms of styrene and aldehyde derivatives indicating the presence of highly localized bonding and nonbonding electrons, respectively.

\section{Conclusion}

In this research, the calculations are done at the M05-2X level. The reaction between styrene derivatives with isobutyraldehyde in the presence of $\mathrm{PhI}(\mathrm{OAc})_{2}$ and $\mathrm{Co}(\mathrm{OAc})_{2}$ was investigated by theoretical methods. Using cheap and readily available aliphatic aldehydes as an alkyl source is a good way to stretch the chain of benzyl esters and would render this decarbonylative alkylative esterification cascade reaction attractive for organic synthesis and medicine chemistry. The reaction energy of styrene derivatives with bromo and chloro substituted at para and meta positions is similar, which is characterized by substitutions having no effect. $\mathrm{Co}^{\mathrm{II}}(\mathrm{OAc})_{2}$ has been used as an efficient catalyst. The greater the difference in values in the parameters $\mu, \eta$, and $\omega$ between the reactants, and the faster the electron transfer and the faster the reaction. According to the shown HOMO and LUMO, we can say that styrene derivatives have as electron donors and the aldehyde radicals have the role of electron acceptor. Contour map of electron density, electron density Laplacian, LOL and ELF of styrene (1a), isobutyraldehyde (2a), and 3-methyl-1-phenylbutyl acetate (3a) molecules were depicted. The blue regions around hydrogen atoms show the delocalized electron. The covalent regions are seen between bonds, indicated by red color with high electron density. The reaction pathway of decarbonylative alkylative esterification of styrene derivatives with aliphatic aldehydes has been computationally studied. The energy of transition states TS1 and TS2 for all compounds were investigated. A mechanism including the $\mathrm{Co}^{\mathrm{II}}-\mathrm{Co}^{\mathrm{III}}-\mathrm{Co}^{\mathrm{I}}$ interconversion was proposed based on the mechanistic and experimental studies.

\section{Data Availability}

The authors express appreciation to the Research Council of the Islamic Azad University of Kerman for supporting this investigation.

\section{Conflicts of Interest}

The authors declare that there are no conflicts of interest. The authors alone are responsible for the content and writing of the paper.

\section{Acknowledgments}

The authors express appreciation to the Research Council of Islamic Azad University of Kerman for supporting this investigation.

\section{References}

[1] X. Guo, J. Wang, and C.-J. Li, “An Olefination via rutheniumcatalyzed decarbonylative Addition of Aldehydes to terminal alkynes," Journal of the American Chemical Society, vol. 131, no. 42, pp. 15092-15093, 2009.

[2] Q. Shuai, L. Yang, X. Guo, O. Baslé, and C.-J. Li, "Rhodiumcatalyzed oxidative $\mathrm{C}-\mathrm{H}$ arylation of 2-arylpyridine derivatives via decarbonylation of aromatic aldehydes," Journal of the American Chemical Society, vol. 132, no. 35, pp. 12212-12213, 2010.

[3] Y. Peng, F. Zhang, T.-T. Qin, C.-L. Xu, and L. Yang, "Regioand stereo-selective decarbonylative alkylative arylation of terminal alkynes with aliphatic aldehydes and arenes via dual $\mathrm{C}-\mathrm{H}$ bond functionalization," Organic Chemistry Frontiers, vol. 6, no. 20, pp. 3597-3602, 2019.

[4] E. Taarning and R. Madsen, "Unsaturated aldehydes as alkene equivalents in the diels-alder reaction," Chemistry-A European Journal, vol. 14, no. 18, pp. 5638-5644, 2008.

[5] M. Brohmer, N. Volz, and S. Brase, "Thieme chemistry journal awardees - where are they now? Microwave-assisted rhodiumcatalyzed decarbonylation of functionalized 3-formyl-2Hchromenes: a sequence for functionalized chromenes like deoxycordiachromene," Synlett, vol. 9, p. 1383, 2009.

[6] J. Hartwig, Organotransition Metal Chemistry: From Bonding to Catalysis, Univ Science Books, Sausalito, CA, 2010.

[7] A. Modak, A. Deb, T. Patra, S. Rana, S. Maity, and D. Maiti, “A general and efficient aldehyde decarbonylation reaction by using a palladium catalyst," Chemical Communications, vol. 48 , no. 35 , p. 4253, 2012.

[8] S. Ortgies, C. Depken, and A. Breder, "Oxidative allylic esterification of alkenes by cooperative selenium-catalysis using air as the sole oxidant," Organic Letters, vol. 18, no. 12, pp. 2856-2859, 2016.

[9] M. A. Garralda, "Aldehyde C-H activation with late transition metal organometallic compounds. Formation and reactivity of acyl hydrido complexes," Dalton Transactions, no. 19, p. $3635,2009$.

[10] K. Sen and J. C. Hackett, "Peroxo-Iron mediated deformylation in sterol $14 \alpha$-demethylase catalysis," Journal of the American Chemical Society, vol. 132, no. 30, pp. 10293-10305, 2010.

[11] T. Patra, S. Manna, and D. Maiti, "Metal-mediated deformylation reactions: synthetic and biological avenues," Angewandte Chemie International Edition, vol. 50, no. 51, pp. 12140-12142, 2011.

[12] J. Tsuji and K. Ohno, "Organic syntheses by means of noble metal compounds XXI. Decarbonylation of aldehydes using rhodium complex," Tetrahedron Letters, vol. 6, no. 44, pp. 3969-3971, 1965.

[13] V. V. Zhdankin and P. J. Stang, "Chemistry of polyvalent iodine," Chemical Reviews, vol. 108, no. 12, pp. 5299-5358, 2008.

[14] Q. Ding, Y. Ye, and R. Fan, "Recent advances in phenol dearomatization and its application in complex syntheses," Synthesis, vol. 45, 2013.

[15] J. Lan, H. Xie, X. Lu, Y. Deng, H. Jiang, and W. Zeng, "Co(II)-Catalyzed regioselective cross-dehydrogenative 
coupling of aryl C-H bonds with carboxylic acids," Organic Letters, vol. 19, no. 16, pp. 4279-4282, 2017.

[16] Y. Wang, L. Zhang, Y. Yang et al., "Alkene oxyalkylation enabled by merging rhenium catalysis with hypervalent iodine(III) reagents via decarboxylation," Journal of the American Chemical Society, vol. 135, no. 48, pp. 18048-18051, 2013.

[17] Z. Wang, M. Kanai, and Y. Kuninobu, "Iron-catalyzed acyloxyalkylation of styrenes using hypervalent iodine reagents," Organic Letters, vol. 19, no. 9, pp. 2398-2401, 2017.

[18] A. Bunescu, Q. Wang, and J. Zhu, "Copper-mediated/catalyzed oxyalkylation of alkenes with alkylnitriles," Chemistry A European Journal, vol. 20, no. 45, pp. 14633-14636, 2014.

[19] Y.-X. Dong, Y. Li, C.-C. Gu, S.-S. Jiang, R.-J. Song, and J.-H. Li, "Copper-catalyzed three-components intermolecular Alkylesterification of Styrenes with Toluenes and Peroxyesters or acids," Organic Letters, vol. 20, no. 23, pp. 7594-7597, 2018.

[20] R. F. W. Bader, Atoms in Molecules, Wiley Online Library, Hoboken, NJ, USA, 1990.

[21] H. Jacobsen, "Localized-orbital locator (LOL) profiles of chemical bonding," Canadian Journal of Chemistry, vol. 86, no. 7, pp. 695-702, 2008.

[22] B. Silvi and A. Savin, "Classification of chemical bonds based on topological analysis of electron localization functions," Nature, vol. 371, no. 6499, pp. 683-686, 1994.

[23] M. Frisch, G. Trucks, H. B. Schlegel et al., "Wallingford CT 19 227," 2009.

[24] R. Bader, AIMPAC: A Suite of Programs for the AIM Theory, McMaster University Hamilton, Ontario, Canada, 2000.

[25] M. Rahimi and P. Nasertayoob, "Dynamical information content of the molecular structures: a quantum theory of atoms in molecules (QTAIM) approach," MATCH Commun. Math Comput. Chem, vol. 33, no. 67, pp. 109-126, 2012.

[26] T. Lu, F. Chen, and J. Comp, "Multiwfn: a multifunctional wavefunction analyzer," Journal of Computational Chemistry, vol. 33, no. 5, pp. 580-592, 2012.

[27] M. P. Andersson, P. Uvdal, and J. Phy, "New scale factors for harmonic vibrational frequencies using the B3LYP density functional method with the triple- $\zeta$ basis set $6-311+\mathrm{G}(\mathrm{d}, \mathrm{p})$," The Journal of Physical Chemistry A, vol. 109, no. 12, pp. 2937-2941, 2005. 